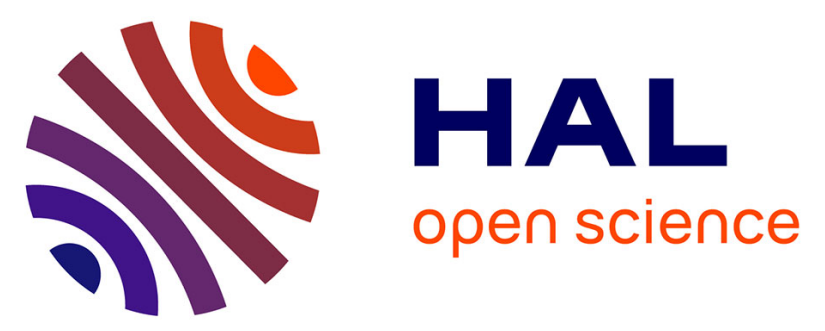

\title{
Status of black-grass (Alopecurus myosuroides) resistance to acetyl-coenzyme A carboxylase inhibitors in France
}

Christophe C. Delye, Yosra Menchari, Jean-Philippe Guillemin, Annick

Matejicek, Séverine S. Michel, Christine C. Camilleri, Bruno B. Chauvel

\section{To cite this version:}

Christophe C. Delye, Yosra Menchari, Jean-Philippe Guillemin, Annick Matejicek, Séverine S. Michel, et al.. Status of black-grass (Alopecurus myosuroides) resistance to acetyl-coenzyme A carboxylase inhibitors in France. Weed Research, 2007, 47 (2), pp.95-105. 10.1111/j.1365-3180.2007.00544.x . hal-02655683

\section{HAL Id: hal-02655683 \\ https://hal.inrae.fr/hal-02655683}

Submitted on 29 May 2020

HAL is a multi-disciplinary open access archive for the deposit and dissemination of scientific research documents, whether they are published or not. The documents may come from teaching and research institutions in France or abroad, or from public or private research centers.
L'archive ouverte pluridisciplinaire HAL, est destinée au dépôt et à la diffusion de documents scientifiques de niveau recherche, publiés ou non, émanant des établissements d'enseignement et de recherche français ou étrangers, des laboratoires publics ou privés. 


\title{
Status of black grass (Alopecurus myosuroides) resistance to acetyl-coenzyme $A$ carboxylase inhibitors in France
}

\author{
C DÉLYE*, Y MENCHARI*, J-P GUILLEMIN†, A MATÉJICEK*, S MICHEL*, \\ C CAMILLERI $\&$ B CHAUVEL* \\ *INRA, UMR1210 Biologie et Gestion des Adventices, F-21000 Dijon, France, †ENESAD, UMR1210 Biologie et Gestion des Adventices, \\ F-21000 Dijon, France, and $¥ I N R A$, Station de Génétique et Amélioration des Plantes, F-78000 Versailles, France
}

Received 9 May 2006

Revised version accepted 4 October 2006

\section{Summary}

We assessed the contributions of target site- and nontarget site-based resistance to herbicides inhibiting acetyl-coenzyme A carboxylase (ACC) in Alopecurus myosuroides (black grass). A total of 243 A. myosuroides populations collected across France were analysed using herbicide sensitivity bioassay (24 300 seedlings analysed) and ACC genotyping (13 188 seedlings analysed). Seedlings resistant to at least one ACC-inhibiting herbicide were detected in $99.2 \%$ of the populations. Mutant, resistant ACC allele(s) were detected in $56.8 \%$ of the populations. Among the five resistant ACC alleles known in A. myosuroides, alleles containing an isoleucine-to-leucine substitution at codon 1781 were predominant $59.5 \%$ of the plants containing resistant ACC alleles). Comparison of the results from herbicide sensitivity bioassays with genotyping indicated that more than $75 \%$ of the plants resistant to ACC-inhibiting herbicides in France would be resistant via increased herbicide metabolism. Analysis of herbicide application records suggested that in $15.9 \%$ of the populations studied, metabolism-based resistance to ACC-inhibiting herbicides was mostly selected for by herbicides with other modes of action. Our study revealed the importance of non-target site-based resistance in A. myosuroides. Using herbicides with alternative modes of action to control populations resistant to ACC-inhibiting herbicides, the recommended management approach, may thus be jeopardised by the widespread occurrence of metabolism-based resistance mechanisms conferring broad-spectrum cross-resistance.

Keywords: acetyl-CoA carboxylase, alomy, bioassay, cultural practice survey, genotyping, herbicide resistance mechanism, large-scale study, metabolism.

Délye C, Menchari Y, Guillemin J-P, MatéJicek A, Michel S, Camilleri C \& Chauvel B (2007) Status of black grass (Alopecurus myosuroides) resistance to acetyl-coenzyme A carboxylase inhibitors in France. Weed Research 47, 95-105.

\section{Introduction}

In modern farming systems, herbicides are most effective in controlling weeds, thus securing and sustaining crop yield and quality. However, increasingly strict regulation, especially in Europe (Kudsk \& Streibig, 2003), together with a significant lack of new herbicides with different modes of action since the 1980s, has led growers to depend upon a restricted range of herbicides to control weeds. The vast majority of these herbicides act by inhibiting single enzymes involved in vital metabolic processes in weeds. Over 183 weed species have thus evolved mechanisms of resistance to herbicides (Heap, 2006). Resistance can severely hamper herbicide-based weed control. To maximise the efficacy of each herbicide treatment and to minimise the environmental impact of herbicide applications, it is necessary to identify the genes

Correspondence: C Délye, INRA, UMR1210 Biologie et Gestion des Adventices, BP 86510, F-21065 Dijon Cedex, France. Tel: (+33) 380 693 185; Fax: (+33) 380693 262; E-mail: delye@dijon.inra.fr 
endowing resistance to herbicides in weeds. It is also crucial to determine which among these genes are most widespread in a weed species, so that they are targeted in priority by integrated management procedures (Buhler et al., 2000).

Alopecurus myosuroides Huds. (black grass) is a diploid, annual, mostly allogamous grass that is a major weed of winter crops in northern Europe. In France, herbicides targeting chloroplastic acetyl-coenzyme A carboxylase (ACC, EC 6.4.1.2.; see Délye, 2005, for a review) have been widely used to control this weed since the end of the 1980s. As a consequence, numerous A. myosuroides populations evolved resistance to these herbicides (Heap, 2006). Resistance to herbicides inhibiting ACC can be due to each of at least five distinct amino-acid substitutions within ACC, the associated cross-resistance patterns of which have been characterised (reviewed in Délye, 2005). Alternatively, resistance to herbicides inhibiting ACC can be due to various metabolism enzymes that detoxify herbicides (reviewed in Délye, 2005). ACC-based resistance is now rather well understood, but the genetic bases for metabolism-based resistance remain very poorly characterised (Délye, 2005). While ACC-based resistance only confers crossresistance to herbicides inhibiting ACC, metabolismbased resistance has been shown to confer crossresistance to herbicides with different modes of action (e.g. Cummins et al., 1999; Letouzé \& Gasquez, 2001). These two mechanisms of resistance to herbicides have therefore quite different consequences in terms of weed management. However, the respective contributions of mutant, resistant ACC alleles and metabolism genes to resistance to ACC-inhibiting herbicides have never been investigated to date in any weed species. This is also true for A. myosuroides, the species in which the genetic basis of resistance to ACC-inhibiting herbicides has been most thoroughly studied (Délye, 2005).
In this study, we assessed the frequencies of plants resistant to ACC-inhibiting herbicides in a total of 243 A. myosuroides populations from France, using seed-based herbicide sensitivity bioassay. We assessed the frequencies of the five mutant, resistant ACC alleles in each population by genotyping, so as to determine whether any mutant, resistant allele was predominant. By comparing results from herbicide sensitivity bioassay and from genotyping in each population, we also estimated the respective contributions of the five mutant, resistant ACC alleles and of non-target site-based resistance to the phenomenon of A. myosuroides resistance to ACC-inhibiting herbicides in France.

\section{Materials and methods}

\section{Plant material}

A total of 243 A. myosuroides populations were used in this study. A first set of 116 populations were sampled in 2000 from fields sown with winter wheat where no satisfactory A. myosuroides control by ACC-inhibiting herbicides was achieved. These populations were mostly collected in north-eastern France (Fig. 1). A second set of populations were sampled in 2003 across the French administrative district of Côte d'Or (roughly $100 \times 130 \mathrm{~km}$ in size; Fig. 1), to check whether the results obtained at a local geographical scale were consistent with those obtained at the national level. All fields sampled in Côte d'Or were sown with winter wheat. They were selected at random and so that coverage of A. myosuroides range in Côte d'Or was as exhaustive and homogeneous as possible. The Châtillonnais forest occurs in the north-west of Côte d'Or, and the Burgundy vineyard is present in the central south. No cereals are grown in these two areas,

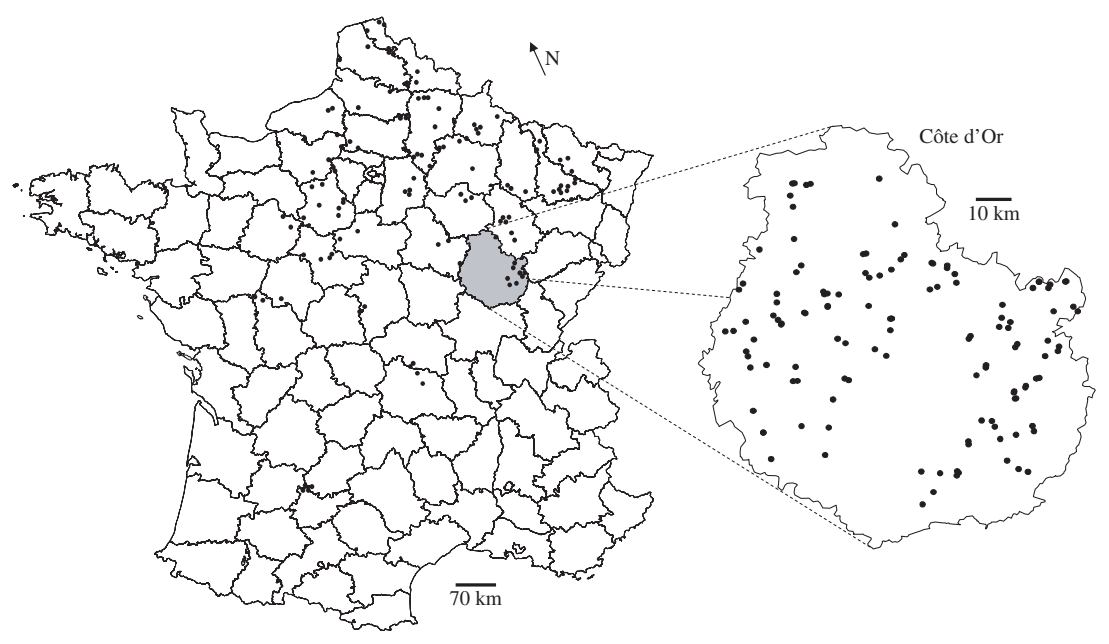

Fig. 1 Map of France with the geographical origins of the 243 black grass populations investigated. The 116 populations from France were collected in 2000 and the 127 populations from Côte d'Or in 2003. 
which where therefore not included in our study (Fig. 1).

In order to ensure an extensive sampling of the variability occurring in each of the 243 A. myosuroides populations sampled, seeds were collected by zigzagging across each field and harvesting all ripe seeds from one or two spikes from 50 to 150 plants. A single bulk sample was thus collected in each field. Seed samples were stored at room temperature for 4 months to allow them a sufficient after-ripening period. Each seed sample was then thoroughly mixed before a subsample was used for herbicide sensitivity bioassay and ACC genotyping.

\section{Analysis of cultural practices}

The record of cultural practices and herbicide applications was surveyed in each of the 243 fields sampled. The main cultural practices considered in our surveys were crop rotation, sowing date, type of soil cultivation and herbicide programme. The frequency of ACC-inhibiting herbicide applications in each field over the period surveyed was expressed as the number of applications per year. Frequencies were then distributed into seven classes reflecting the intensity of the selection exerted by ACC-inhibiting herbicides. The limits of the intervals of class of frequencies were chosen so that they had a relevant agronomical meaning, i.e. one herbicide application every 2 years $(0.5)$, three applications in 4 years (0.75), and one, two and more than two applications per year. The correlation between the frequencies of ACCinhibiting herbicide applications and the proportions of plants resistant to ACC-inhibiting herbicides or the proportions of the five mutant, resistant ACC alleles detected in A. myosuroides populations was estimated using the Spearman coefficient computed with the FREQ procedure in the SAS software (SAS Institute, Cary, NC, USA).

\section{Herbicide sensitivity bioassay}

In France, selection for resistance to ACC-inhibiting herbicides in A. myosuroides has mostly been due to two herbicides, fenoxaprop (Fx) and/or clodinafop (Cd). Sensitivity of $A$. myosuroides seedlings was thus assessed to these herbicides using a previously described seedbased bioassay (Letouzé \& Gasquez, 1999). The commercial formulations used were Puma LS (69 $\mathrm{g} \mathrm{L}^{-1} \mathrm{Fx}$; Aventis France, Gif-sur-Yvette, France) and Célio (100 $\mathrm{g} \mathrm{L}^{-1} \mathrm{Cd}$; Evolya, Rueil-Malmaison, France). The concentrations discriminating resistant from sensitive seedlings were $30 \mu \mathrm{M}$ for Fx and $15 \mu \mathrm{M}$ for $\mathrm{Cd}$. One hundred seedlings were assayed per population and per herbicide.

\section{DNA extraction}

Seeds from each population were placed in growth chambers $\left(12 \mathrm{~h}\right.$ day, $\left.20^{\circ} \mathrm{C}\right)$ in $9 \times 9 \times 9 \mathrm{~cm}$ transparent plastic boxes containing $3 \mathrm{~mm}$ diameter glass beads supporting one leaf of blotting paper and soaked with $25 \mathrm{~mL}$ of $20 \mathrm{~mm} \mathrm{KNO}_{3}$ solution. About 50 seeds were deposited per box. After 7 days, a $1 \mathrm{~cm}$ section of the first leaf of seedlings taken at random was cut and placed together with a glass bead ( $2 \mathrm{~mm}$ diameter) into a $0.2 \mathrm{~mL}$ microcentrifuge tube containing $75 \mu \mathrm{L}$ of extraction buffer $[100 \mathrm{~mm}$ Tris- $\mathrm{HCl}, \mathrm{pH}=9.5,1 \mathrm{M} \mathrm{KCl}$, $10 \mathrm{~mm}$ ethylenediaminetetraacetic acid (EDTA)]. Leaf fragments were disrupted using a bead mill (TissueLyser, Qiagen France, Courtaboeuf, France). Tubes were placed in a water bath at $95^{\circ} \mathrm{C}$ for 6 min, transferred into ice for $5 \mathrm{~min}$ and vortexed for $15 \mathrm{~s}$. DNA extracts were diluted 50 -fold and kept at $-20^{\circ} \mathrm{C}$ prior to genotyping. DNA was extracted from 48 seedlings from each of the 116 populations collected in 2000 across France and from 60 seedlings from each of the 127 populations collected in 2003 in Côte d'Or.

\section{ACC genotyping}

The five amino-acid substitutions within the ACC protein sequence that confer resistance to ACC-inhibiting herbicides are caused by seven point mutations within the gene encoding ACC. The amino-acid substitutions are Ile-1781-Leu (two mutations), Trp-2027-Cys (two mutations), Ile-2041-Asn, Asp-2078-Gly and Gly2096-Ala (Délye et al., 2002a, 2003, 2005). In the following, the five mutant, resistant ACC alleles will be referred to as L1781, C2027, N2041, G2078 and A2096 respectively. Genotyping was performed by MALDI-TOF mass spectrometry using the 'GOOD Assay' single-nucleotide polymorphism analysis procedure (Sauer et al., 2000) with primers listed in Table 1.

\section{Contribution of mutant, resistant ACC alleles to herbicide resistance}

In our seed-based bioassays, plants containing one or two L1781 ACC allele(s) were resistant to Fx but sensitive to $\mathrm{Cd}$ (Délye et al., 2002b), while plants containing at least one of any other ACC alleles were resistant to both herbicides (Délye et al., 2003, 2005). This, and the respective frequencies of plants containing each of the five mutant ACC alleles within each population determined by genotyping, enabled computation of the proportions of plants expected to be resistant to $\mathrm{Fx}$ or to $\mathrm{Cd}$ if the five mutant ACC alleles explained the whole of resistance. These expected 
98 C Délye et al.

Table 1 Extension primers used for genotyping ACC in black-grass by MALDI-TOF mass spectrometry

\begin{tabular}{|c|c|c|c|c|}
\hline \multirow[b]{2}{*}{ Primer } & \multirow[b]{2}{*}{ Sequence* } & \multicolumn{3}{|c|}{ Nucleotide targeted (amino-acid encoded) } \\
\hline & & Position $\uparrow$ & Wild-type & Mutant \\
\hline SP1781: & AGGATGGACTAGGTGTGGAGA-ptA-ptC & 5341 & A (I1781) & $\mathrm{C} / \mathrm{T}(\mathrm{L} 1781)$ \\
\hline SP2027§ & ACCTCTGTTCATACTTGCTAAC-ptT-ptG & 6081 & G (W2027) & C/T (C2027) \\
\hline SP2041§ & GGCAAAGAGATCTTTTTGAAG-ptG-ptA-ptA & 6122 & $\mathrm{~T}(\mathrm{I} 2041)$ & A (N2041) \\
\hline SP2078§ & GGAGGAGCCTGGGTCGTGAT-ptT-ptG & 6233 & A (D2078) & G (G2078) \\
\hline SP2096§ & TGCTATGCTGAGAGGACTGCAAA-ptG-ptG & 6287 & G (G2096) & C (A2096) \\
\hline
\end{tabular}

*pt, phosphorothioate bridge.

$\uparrow$ Nucleotide position in the coding sequence of the gene encoding ACC in black grass (EMBL accession AJ310767).

\$Used after amplification with primers ACVRG1 (5'-AATGGGTCGTGGGGCACTCCTATAATTCC) and ACVRG1R (5'GCTGAGCCACCTCAATATATIAGAAACACC)

§Used after amplification with primers ACVII-2 (5'-GGAGACACAGACCATGATGCAGCTCG) and ACVII-29R (5'CTTCCATTTGCTCCCTGGAGTCTTG).

proportions were compared with the observed values obtained from herbicide bioassays.

\section{Results}

Frequencies of resistant seedlings observed in A. myosuroides populations

Of 24300 seedlings assayed for sensitivity to Fx, 18350 $(75.5 \%)$ were identified as resistant. They consisted of 8180 seedlings from the 116 populations from France (70.5\% of the seedlings assayed) and 10,170 seedlings from the 127 populations from Côte d'Or $(80.1 \%$ of the seedlings assayed). Bioassays performed with $\mathrm{Cd}$ identified a total of 5935 resistant seedlings of the 24300 assayed $(24.4 \%)$. They consisted of 3570 seedlings from the 116 populations from France $(30.8 \%)$ and 2365 seedlings from the 127 populations from Côte d'Or (18.6\%).

Among the 243 populations studied, only two (0.8\%) did not contain any seedling resistant to Fx (Fig. 2). Both were collected in France in 2000. The vast majority (221) of the 241 remaining populations contained more than $50 \%$ seedlings that were resistant to $\mathrm{Fx}$ in our bioassay (Fig. 2). Thirty-four populations (14.0\%) did not contain any seedling resistant to $\mathrm{Cd}$ in our bioassay (Fig. 2). They

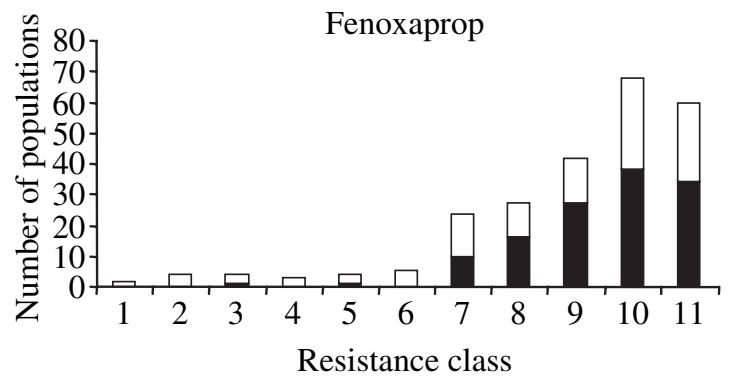

consisted of seven populations from Côte d'Or and 27 populations from France. The majority (136) of the remaining 209 populations contained <31\% seedlings that were resistant to $\mathrm{Cd}$ in our bioassay (Fig. 2). The distribution of populations across resistance classes was similar in the 127 populations from Côte d'Or that were collected at random and in the 116 populations from France that were collected from fields where no satisfactory A. myosuroides control was achieved (Fig. 2).

\section{Occurrence of mutant ACC alleles in A. myosuroides populations from France and from Côte d'Or}

Of 13188 seedlings genotyped, 10594 (80.4\%) did not contain any of the five known mutant, resistant ACC alleles (Table 2). Two types of mutant ACC alleles (e.g. L1781/N2041) were found in 118 seedlings (0.9\%). All 10 combinations of two different mutant ACC alleles that are possible within a single plant were observed among the 118 seedlings. The remaining seedlings, either homozygous (e.g. L1781/L1781) or heterozygous (e.g. L1781/ wild-type), contained a single type of mutant ACC allele.

None of the five mutant alleles was detected in 105 populations (Table 3). In 137 of the 138 remaining populations, at least one seedling did not contain any

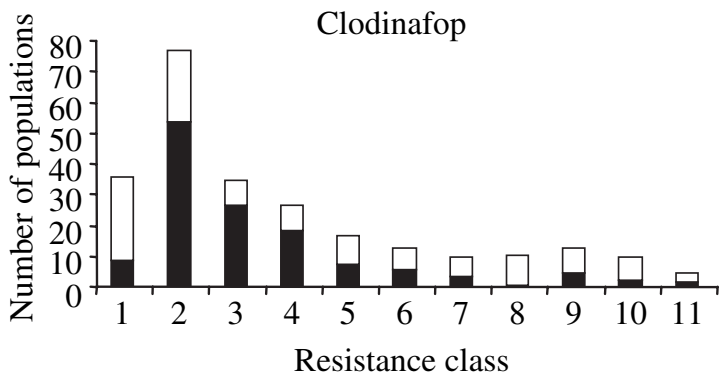

Fig. 2 Distribution of 243 black grass populations across classes of resistance to Fx (left) or to Cd (right). Open bars, populations collected in France in 2000 (116 populations). Solid bars, populations collected in Côte d'Or in 2003 (127 populations). Populations classes: $1=0 \%$; $2=1-10 \% ; 3=11-20 \% ; 4=21-30 \% ; 5=31-40 \% ; 6=41-50 \% ; 7=51-60 \% ; 8=61-70 \% ; 9=71-80 \% ; 10=81-90 \% ; 11=91-$ $100 \%$ resistant plants. Resistant plants were identified using seed-based bioassays. 
Table 2 Occurrence of the five mutant, resistant ACC alleles among 13188 black grass seedlings

\begin{tabular}{|c|c|c|c|}
\hline $\begin{array}{l}\text { Mutant, resistant } \\
\text { ACC allele detected }\end{array}$ & $\begin{array}{l}\text { Seedlings in the } \\
\text { populations from } \\
\text { France, no. }(\%)^{*}\end{array}$ & $\begin{array}{l}\text { Seedlings in the } \\
\text { populations from } \\
\text { Côte d'Or, no. (\%)† }\end{array}$ & Total, no. (\%) \\
\hline None & $3654(65.7)$ & $6940(91.1)$ & $10594(80.4)$ \\
\hline L1781 & 1109 A£ (19.9) & $435 \mathrm{~A}(5.7)$ & 1544 A (11.7) \\
\hline C2027 & 298 B (5.3) & 3 B (0.04) & 301 B (2.3) \\
\hline N2041 & 147 C (2.6) & 175 C (2.3) & 322 B (2.4) \\
\hline G2078 & 70 D (1.3) & $25 \mathrm{D}(0.3)$ & 95 C (0.7) \\
\hline A2096 & 202 E (3.6) & $12 B, D(0.2)$ & 214 D (1.6) \\
\hline Two & $88(1.6)$ & $30(0.4)$ & $118(0.9)$ \\
\hline Total & $5568(100.0)$ & $7620(100.0)$ & $13188(100.0)$ \\
\hline
\end{tabular}

*Of the 5568 seedlings genotyped in the 116 populations from France.

$\dagger$ Of the 7620 seedlings genotyped in the 127 populations from Côte d'Or.

$\$$ Of the 13188 seedlings genotyped in the 243 populations studied.

$\S$ Values with identical letters within a column are not significantly distinct according to the two-sample test for equality of proportions with continuity correction at the $5 \%$ level after Bonferroni correction.

$\uparrow$ Two types of mutant, resistant ACC alleles (e.g. L1781/N2041) detected in each seedling.

Table 3 Occurrence of the five mutant, resistant ACC alleles across 243 black grass populations

\begin{tabular}{|c|c|c|c|c|c|c|}
\hline \multirow[b]{2}{*}{ Black grass population sample } & \multicolumn{6}{|c|}{ Mutant, resistant ACC allele detected } \\
\hline & None & L1781 & C2027 & N2041 & G2078 & A2096 \\
\hline \multicolumn{7}{|l|}{ All 243 populations } \\
\hline Number of populations where detected & 105 & $99 A^{*}$ & $22 \mathrm{~B}$ & $45 \mathrm{C}$ & $27 \mathrm{~B}, \mathrm{C}, \mathrm{D}$ & $21 \mathrm{~B}, \mathrm{D}$ \\
\hline Minimal frequency when detected $(\%) \dagger$ & NA & 1.7 & 1.7 & 1.7 & 1.7 & 1.7 \\
\hline Average frequency in populations where detected $(\%) \dagger$ & NA & 30.6 & 28.4 & 14.4 & 9.3 & 20.9 \\
\hline Maximal frequency $(\%) \dagger$ & NA & 100.0 & 91.5 & 90.4 & 66.0 & 93.6 \\
\hline \multicolumn{7}{|l|}{116 populations from France } \\
\hline Number of populations where detected & 41 & $48 \mathrm{~A}$ & $20 \mathrm{~B}$ & $18 \mathrm{~B}$ & $17 \mathrm{~B}$ & $17 \mathrm{~B}$ \\
\hline Minimal frequency when detected $(\%) \dagger$ & NA & 2.1 & 2.1 & 2.1 & 2.1 & 2.1 \\
\hline Average frequency in populations where detected $(\%) \dagger$ & NA & 48.2 & 31.0 & 19.1 & 12.1 & 24.7 \\
\hline Maximal frequency $(\%) \dagger$ & NA & 100.0 & 91.5 & 90.4 & 66.0 & 93.6 \\
\hline \multicolumn{7}{|l|}{127 populations from Côte d'Or } \\
\hline Number of populations where detected & 64 & $51 \mathrm{~A}$ & $2 \mathrm{~B}$ & $27 \mathrm{C}$ & $10 \mathrm{~B}, \mathrm{D}$ & $4 \mathrm{~B}, \mathrm{D}$ \\
\hline Minimal frequency when detected $(\%) \dagger$ & NA & 1.7 & 1.7 & 1.7 & 1.7 & 1.7 \\
\hline Average frequency in populations where detected $(\%) \dagger$ & NA & 14.2 & 2.5 & 11.2 & 4.5 & 5.0 \\
\hline Maximal frequency $(\%) \dagger$ & NA & 90.0 & 3.4 & 81.6 & 25.0 & 10.0 \\
\hline
\end{tabular}

*Values with identical letters within a row indicate frequencies that are not significantly distinct according to the two-sample test for equality of proportions with continuity correction at the $5 \%$ level after Bonferroni correction.

$\dagger \%$ of the seedlings genotyped in a population.

$\$$ Not applicable.

of the five types of mutant alleles. In the remaining population (from France), all seedlings genotyped contained L1781 ACC alleles (Table 3). Eighty-one populations (43 from France, 38 from Côte d'Or) contained a single type of mutant allele, 44 (24 from France, 20 from Côte d'Or) contained two types of mutant alleles, nine (four from France, five from Côte d'Or) contained three types of mutant alleles, and three and one populations, all from France, contained four and five types of mutant alleles respectively. The frequencies of seedlings containing each type of mutant, resistant ACC allele varied broadly between populations (Table 3). However, seedlings containing mutant alleles were detected in higher frequencies in the 116 populations from France $(34.3 \%)$ than in the 127 populations from Côte d'Or (8.9\%). Among the seedlings genotyped, seedlings containing L1781 ACC alleles were largely predominant both in France and in Côte d'Or (Table 2). This was also observed at the level of the populations, with L1781 alleles being detected in the highest number of populations both in France and in Côte d'Or (Table 3). Although their respective frequencies varied between France and Côte d'Or, the four other types of mutant alleles were all detected in frequencies significantly lower than those of L1781 ACC alleles (Tables 2 and 3). 


\section{Contribution of mutant, resistant ACC alleles to herbicide resistance}

The contribution of the five mutant alleles known to date to the resistance of $A$. myosuroides to ACCinhibiting herbicides was assessed by comparing the results of the seed-based bioassays with those of ACC genotyping (Fig. 3). The seedlings used for ACC genotyping were not the same seedlings in which sensitivity was assessed using seed-based bioassays. Given that variability exists within $A$. myosuroides populations, we considered that observed and expected frequencies of resistant seedlings matched when their difference was $<10 \%$. With this assumption, no deficit in the observed frequencies of seedlings resistant to $\mathrm{Fx}$ or to $\mathrm{Cd}$ was observed compared with the expected frequencies (Fig. 3). However, even with the rather broad 10\% margin, comparison between the observed and expected proportions of seedlings resistant to $\mathrm{Fx}$ revealed an excess of observed resistant seedlings in 78 populations from France and in 124 populations from Côte d'Or (Fig. 3; Table 4). In the 78 populations from France, we found that $59.2 \%$ of the Fx-resistant seedlings were expected not to contain any of the five types of mutant ACC alleles conferring resistance to $F x$. This proportion was $89.7 \%$ in the 124 populations from Côte d'Or. Similar results were obtained for $\mathrm{Cd}$. Comparison between the observed and expected proportions of seedlings resistant to $\mathrm{Cd}$ revealed an excess of observed resistant seedlings in 47 populations from France and in 61 populations from Côte d'Or (Fig. 3; Table 4). In the 47 populations from France, we found that $67.8 \%$ of the
Cd-resistant seedlings were expected not to contain any of the four types of mutant ACC alleles conferring resistance to $\mathrm{Cd}$. This proportion was $88.5 \%$ in the 61 populations from Côte d'Or. Overall, $75.1 \%$ of the Fxresistant seedlings and $78.6 \%$ of the Cd-resistant seedlings were expected not to contain any mutant alleles conferring resistance to these herbicides.

\section{Impact of cultural practices upon resistance to ACC-inhibiting herbicides}

The records of cultural practices and herbicide applications obtained for the 243 fields sampled in France and Côte d'Or ranged across 6 years on average. Ten surveys (four from France and six from Côte d'Or) were too incomplete to be analysed. Survey analyses were thus conducted upon a total of 233 populations (112 populations from France and 121 from Côte d'Or). The diversity of cultural practices performed by growers was very high at both regional and national scales and no correlation could be drawn with the observed proportions of resistant plants. We consequently focused the analyses upon the herbicide spraying programmes. A total of 76 and 61 herbicide molecules, comprising 19 and 14 herbicide modes of action, were sprayed over the fields investigated in France and Côte d'Or respectively. Among these herbicide molecules, a total of 10 and six ACC-inhibiting molecules were sprayed across 196 of the fields surveyed in France and in Côte d'Or respectively. No ACC-inhibiting herbicide application was recorded in the 37 remaining fields (five from France, 32 from Côte d'Or) (Figs 4 and 5). In winter wheat, Fx
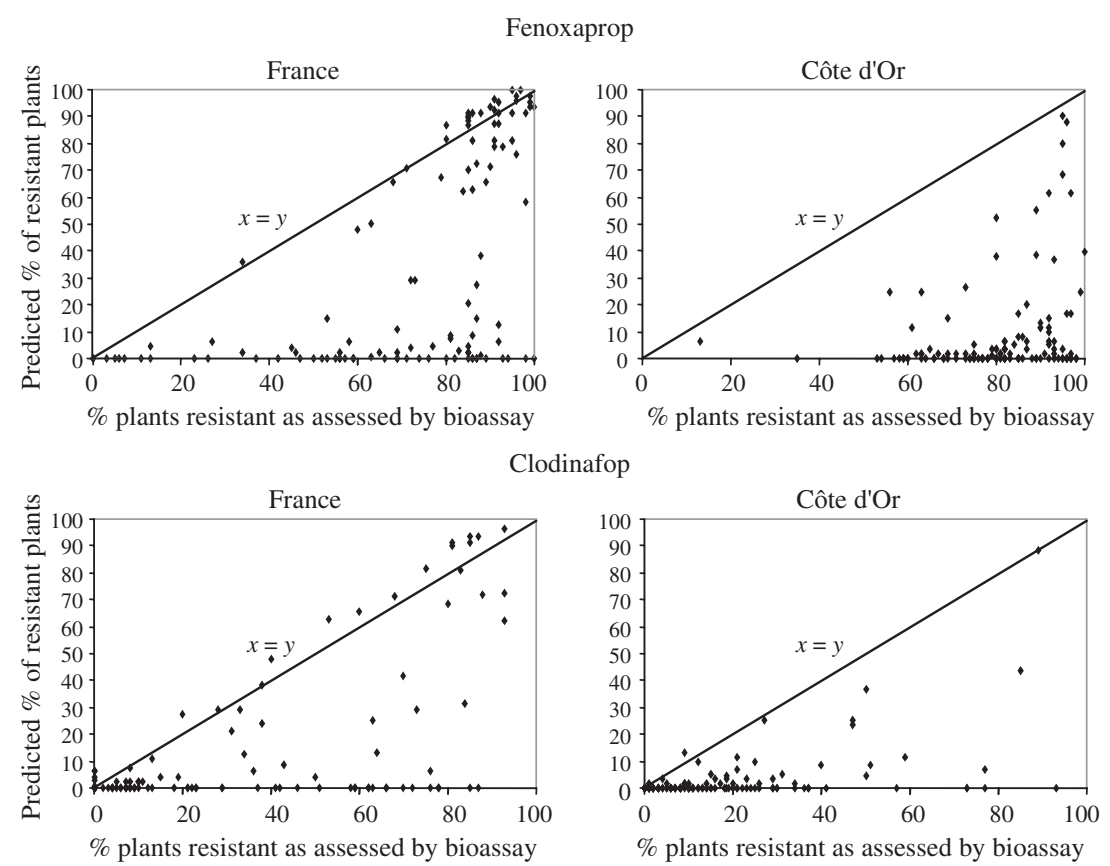

Fig. 3 Comparison of the proportions of black grass seedlings resistant to Fx (top) or to Cd (bottom) observed in seed-based bioassays with the proportions of seedlings expected to be resistant if the five mutant ACC alleles would explain the whole of resistance, computed using the results of ACC genotyping. Each population from France (left) and each population from Côte d'Or (right) is represented as a dot. 
Table 4 Distribution of the excess of observed versus expected seedlings resistant to two ACC-inhibiting herbicides across 243 black grass populations

\begin{tabular}{|c|c|c|c|c|c|c|}
\hline \multirow[b]{3}{*}{ Herbicide } & \multicolumn{6}{|c|}{ Number of populations with an excess of observed resistant seedlings } \\
\hline & \multicolumn{3}{|c|}{ In France (of 116 populations) } & \multicolumn{3}{|c|}{ In Côte d'Or (of 127 populations) } \\
\hline & $\begin{array}{l}\text { With mutant, } \\
\text { resistant } A C C \text { allele(s) }\end{array}$ & $\begin{array}{l}\text { Without mutant, } \\
\text { resistant ACC allele }\end{array}$ & Total & $\begin{array}{l}\text { With mutant, } \\
\text { resistant } A C C \text { allele(s) }\end{array}$ & $\begin{array}{l}\text { Without mutant, } \\
\text { resistant ACC allele }\end{array}$ & Total \\
\hline Fenoxaprop & 43 & 35 & 78 & 60 & 64 & 124 \\
\hline Clodinafop & 40 & 7 & 47 & 40 & 21 & 61 \\
\hline
\end{tabular}

A

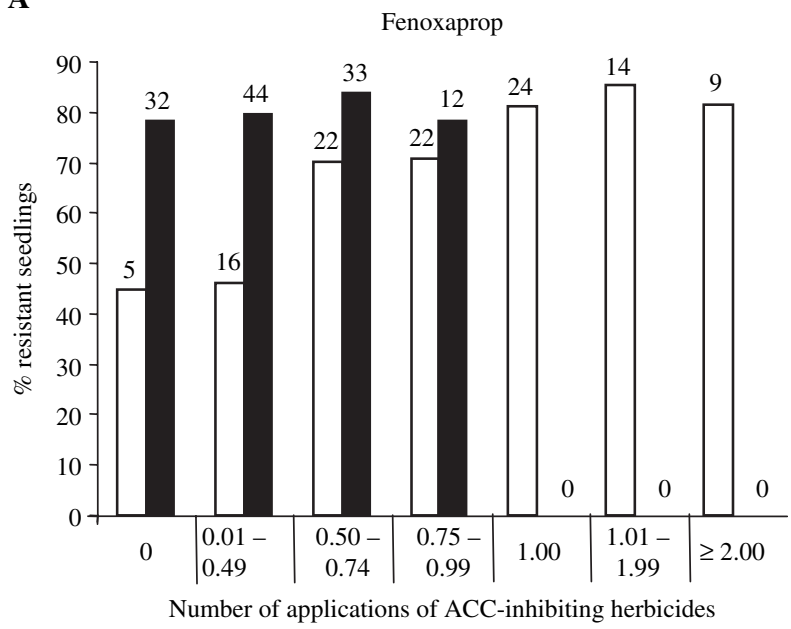

B

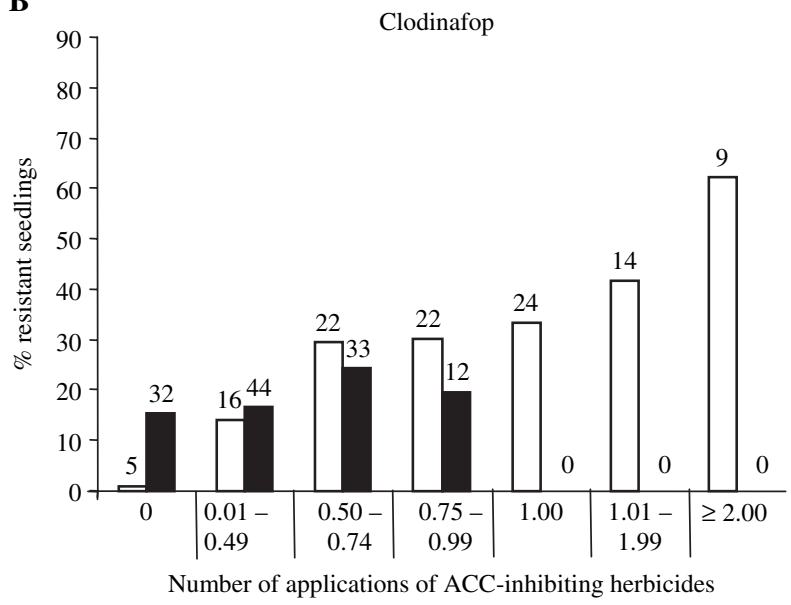

Fig. 4 Number of applications of ACC-inhibiting herbicides per year plotted against the mean frequency of Fx-resistant seedlings (A) or Cd-resistant seedlings (B) observed in black grass populations in each class of ACC-inhibiting herbicide application frequency. Open bars, populations collected in France in 2000 (112 populations). Solid bars, populations collected in Côte d'Or in 2003 (121 populations). Numbers above bars correspond to the number of black grass populations.

and $\mathrm{Cd}$ were clearly the most frequently used ACCinhibiting herbicides both in France and in Côte d'Or. The mean frequency of application of ACC-inhibiting herbicides was 0.89 year $^{-1}$ in France and 0.35 year $^{-1}$ in

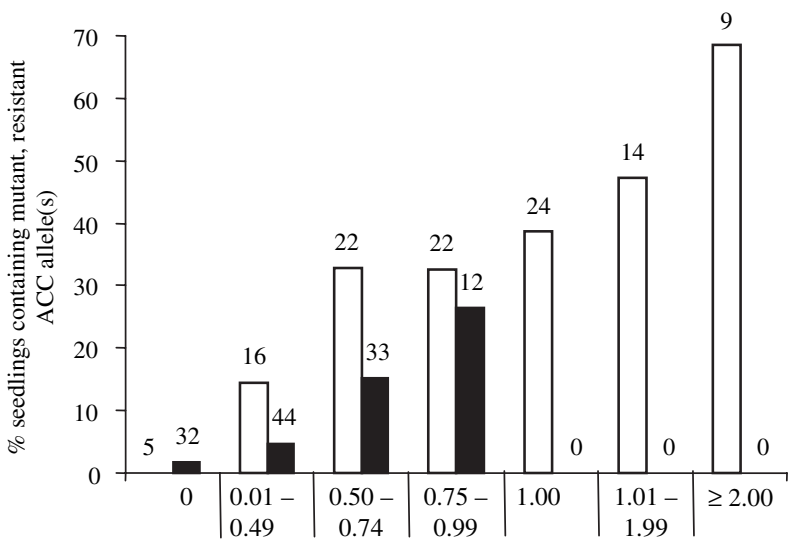

Number of applications of ACC-inhibiting herbicides

Fig. 5 Number of applications of ACC-inhibiting herbicides per year plotted against the mean frequency of mutant, resistant ACC alleles detected in black grass populations in each class of ACCinhibiting herbicide application frequency. Open bars, populations collected in France in 2000 (112 populations). Solid bars, populations collected in Côte d'Or in 2003 (121 populations). Numbers above bars correspond to the number of black grass populations.

Côte d'Or. None of the fields surveyed in Côte d'Or received more than one ACC-inhibiting herbicide application per year (Fig. 4), while this number was up to three in France.

In France, the mean proportion of plants resistant to Fx or $\mathrm{Cd}$ increased with the number of ACC-inhibiting herbicide applications (Fig. 4; $r=0.46, P<10^{-3}$ for Fx and $r=0.44, P<10^{-3}$ for $\left.\mathrm{Cd}\right)$. The situation in Côte d'Or was rather dissimilar, where the mean proportion of plants resistant to $\mathrm{Fx}$ or $\mathrm{Cd}$ varied little with the number of ACC-inhibiting herbicide applications (Fig. 4; $r=0.14, P<10^{-3}$ for Fx and $r=0.24$, $P<10^{-3}$ for $\left.\mathrm{Cd}\right)$.

No mutant, resistant ACC allele was detected in populations from France collected in fields where no ACC-inhibiting herbicide application was recorded (Fig. 5). However, mutant alleles were detected in eight fields from Côte d'Or where no ACC-inhibiting herbicide application was recorded in the cultural practice surveys, i.e. for 3-7 years prior to seed collection 
Table 5 Occurrence of mutant, resistant ACC alleles in eight black grass populations from Côte d'Or collected in fields where no ACC-inhibiting herbicide applications were recorded in surveys

\begin{tabular}{lll}
\hline Population & $\begin{array}{l}\text { Mutant ACC allele(s) } \\
\text { detected (\%)* }\end{array}$ & $\begin{array}{l}\text { Number of } \\
\text { years surveyed }\end{array}$ \\
\hline $0-1$ & L1781 (1.7) & 3 \\
$0-2$ & L1781 (1.7) & 7 \\
$0-3$ & L1781 (25) & 6 \\
$0-4$ & L1781 (3.3) & 4 \\
$0-5$ & L1781 (5.0), N2041 (3.3) & 7 \\
$0-6$ & L1781 (1.7) & 7 \\
$0-7$ & L1781 (10.0), G2078 (1.7) & 3 \\
$0-8$ & G2078 (1.7) & 7 \\
\hline
\end{tabular}

$* \%$ of the seedlings genotyped in a population.

(Table 5). In these fields, the frequencies of mutant alleles detected ranged from $1.7 \%$ to $25.0 \%$ (Table 5). The frequency of mutant alleles detected in populations collected in fields sprayed with ACC-inhibiting herbicides increased with the number of herbicide applications (Fig. 5) $\left(r=0.39, P<10^{-3}\right.$ France; $r=0.41$, $P<10^{-3}$ Côte d'Or).

\section{Discussion}

This is the largest study ever conducted to investigate the extent and the genetic basis of resistance to herbicides in a weed species. Assessment of the sensitivity of a total of 48600 seedlings from 243 populations (Fig. 1) using seed-based bioassay revealed that resistance to the two major ACC-inhibiting herbicides used in France, Fx and $\mathrm{Cd}$, was very widespread. Although the populations from France were sampled in fields where A. myosuroides control using ACC-inhibiting herbicides was not satisfactory, while populations from Côte d'Or were sampled at random, the results obtained for both sets of populations were similar. Seedlings resistant to Fx were identified in 241 of the 243 populations investigated. Most of these populations contained Fx-resistant seedlings in high frequencies (Fig. 2). From our seed-based bioassay results, resistance to $\mathrm{Cd}$ was less widespread (Fig. 2), with a higher frequency of Fx-resistant seedlings than Cd-resistant seedlings observed both nationally and locally. These differences suggest that mechanisms conferring resistance to $\mathrm{Fx}$ do not necessarily confer resistance to $\mathrm{Cd}$. This is consistent with our previous finding that plants containing L1781 ACC alleles are resistant to $\mathrm{Fx}$ but not to $\mathrm{Cd}$ in our seedbased bioassay (Délye et al., 2002b). Moreover, metabolism-based resistance to ACC-inhibiting herbicides belonging to the same chemical family, like Fx and $\mathrm{Cd}$, can be due to distinct metabolic enzymes (e.g. McFadden et al., 1989; Tal et al., 1993). Fx has been marketed since 1988 in France and widely used before Cd was marketed in 1993. Fx thus selected for any mechanism conferring resistance to this particular herbicide. Clearly, only some of these mechanisms conferred cross-resistance to $\mathrm{Cd}$.

Among the 32 populations from Côte d'Or collected in fields where no application of ACC-inhibiting herbicides was recorded, eight populations containing mutant alleles were observed (Fig. 4; Table 5). A possible origin for these alleles could be dissemination from other fields infested with A. myosuroides. Alternatively, these mutant alleles could have been selected for by ACCinhibiting herbicides applied before the period surveyed (Table 5). This is very likely the case for populations with a high proportion of plants containing resistant alleles (population 0-3; Table 5) or for populations where several mutant alleles were detected (populations 0-5 and 0-7; Table 5). This, together with our not identifying cultural practices that may favour resistance, illustrates the limits of surveys to explain selection for herbicide resistance. Another illustration is the positive correlation between the number of ACC-inhibiting herbicide applications in a field and the frequency of Fx-resistant and Cd-resistant seedlings in the corresponding A. myosuroides populations observed in France (Fig. 4). Albeit expected, this relationship should be viewed cautiously. Although ACC-inhibiting herbicides kill $95 \%$ of sensitive plants when properly applied (Foster et al., 1993), their efficacy may vary substantially depending on the growth stage of the weed (Milner et al., 2001), weed physiology and environmental factors inducing high evapotranspiration (Collings et al., 2003). In Côte d'Or, a weak relationship was observed between the number of ACC-inhibiting herbicide applications in a field and the frequency of Fx-resistant and Cdresistant seedlings in the corresponding population (Fig. 4). This, and the very high proportions of Fxresistant seedlings observed in Côte d'Or (Fig. 4A), suggested that resistance evolved and developed before the period surveyed. Thus, the number of applications of ACC-inhibiting herbicides recorded in surveys may not accurately reflect the selective pressure exerted upon A. myosuroides populations.

Herbicide molecules with a total of 19 distinct modes of action were applied across the 233 fields for which the cultural practice surveys were analysed. A high number of seedlings resistant to Fx and some seedlings resistant to $\mathrm{Cd}$ were observed in $A$. myosuroides populations collected from a total of 37 fields where no application of ACC-inhibiting herbicides was recorded (Fig. 4). The large majority of these seedlings were expected not to contain any mutant alleles. Selection for genes endowing cross-resistance to ACC-inhibiting herbicides and to herbicides with a distinct mode of action has already been observed in A. myosuroides and was shown to be 
due to enhanced herbicide metabolism (Cummins et al., 1999; Letouzé \& Gasquez, 2001). Thus, our results strongly suggest that, in the 37 populations in question, resistance to $\mathrm{Fx}$ or $\mathrm{Cd}$ was mostly a side-effect of the selection for metabolism-based resistance to herbicides with mode(s) of action other than ACC inhibition.

Metabolism-based resistance to ACC-inhibiting herbicides had already been observed in $A$. myosuroides populations from France, the UK and Spain (reviewed in Délye, 2005). However, the relative contributions of enhanced metabolism and resistant ACC alleles to the resistance of $A$. myosuroides had never been examined before. Our study showed that, in the 243 populations analysed, $75.1 \%$ of the Fx-resistant seedlings and $78.6 \%$ of the Cd-resistant seedlings were expected not to contain any of the five known mutant alleles. This highlights the considerable significance of other resistance mechanisms in $A$. myosuroides. These can be unknown mutant ACC alleles, or enhanced herbicide metabolism, or both. Several distinct genes endowing resistance to ACC-inhibiting herbicides can coexist in a single $A$. myosuroides population, as observed herein in a total of 202 and 108 populations where known mutant ACC alleles were not the sole basis for resistance to Fx or $\mathrm{Cd}$, respectively (Table 4 and Fig. 3). Several resistance genes can also coexist in a single $A$. myosuroides plant, as observed herein (Table 2) and reported elsewhere in A. myosuroides (Letouzé \& Gasquez, 2001) and in other grass weeds (e.g. Maneechote et al., 1997; VilaAiub et al., 2005a). Mutant ACC alleles other than the five already known probably exist in A. myosuroides. ACC is a gene under strong purifying selection (Délye et al., 2004) and the amino-acid domains crucial for sensitivity to ACC-inhibiting herbicides are of a restricted size (Délye et al., 2005), implying that these alleles are probably not numerous. Sequencing the gene encoding ACC in 86 A. myosuroides plants from 18 populations from France revealed potential new mutant, resistant alleles in very low frequencies (Délye et al., 2004). It is thus unlikely that such alleles are responsible for the main part of resistance that is not due to the five alleles already identified. Thus, enhanced herbicide metabolism is probably the basis for most of the resistance to ACC-inhibiting herbicides in French A. myosuroides populations. Metabolism-based resistance is poorly understood, especially at the level of the gene. Given its widespread occurrence, its major role in resistance and the possibility of cross-resistance to herbicides with other modes of action, metabolismbased resistance is clearly a facet of resistance that needs to be thoroughly investigated in order to develop resistance diagnosis tools and to propose efficient resistance management strategies. Alternative use of herbicides with different target sites is predicted by models to significantly reduce the selection for resistance (Jasieniuk et al., 1996; Cavan et al., 2000, 2001). Another possibility is spraying tank-mixed herbicides with different modes of action (e.g. Diggle et al., 2003), although in this case the possible antagonism between herbicides must also be considered (e.g., Barnes \& Oliver, 2004). Sprayer technology is now sufficiently developed such that mosaic spraying strategies, that is spraying strips in the same field with herbicides with distinct modes of action (Roux et al., 2004), may also become a relevant option. In $A$. myosuroides, metabolism-based resistance has been demonstrated to confer cross-resistance to ACC-inhibiting and peroxidising herbicides (Cummins et al., 1999), or to ACC-inhibiting and acetolactate synthase-inhibiting herbicides (Letouzé \& Gasquez, 2001). Herbicide-based weed management tactics must therefore consider broad-spectrum crossresistance due to metabolism-based resistance mechanisms when choosing alternative herbicides.

Acetyl-coenzyme A carboxylase genotyping revealed the occurrence of mutant, resistant ACC alleles in A. myosuroides across France. The respective frequencies of the five alleles studied were highly variable among populations (Table 3). However, L1781 ACC alleles were present in $59.5 \%$ of $A$. myosuroides seedlings containing mutant, resistant ACC alleles (Table 2) and were clearly predominant in both France and Côte d'Or (Tables 2 and 3). A possible explanation for this would be a fitness penalty lower than those associated with any of the four other known alleles. This is consistent with L1781 ACC alleles being most often observed across grass species resistant or inherently tolerant to ACCinhibiting herbicides (Délye, 2005; Délye \& Michel, 2005). This could also account for the detection of as much as $25.0 \%$ plants containing L1781 alleles in a field where no ACC-inhibiting herbicide application was recorded for at least 6 years (population 0-3; Table 5).

There is no published data exploring fitness penalties associated with C2027, N2041, G2078 or A2096 ACC alleles. A single study has concluded an absence of any fitness penalty on vegetative and reproductive growth for plants containing L1781 ACC alleles in the Lolium rigidum Gaud. population studied (Vila-Aiub et al., 2005b), thus supporting our hypothesis. This work also showed a reduced aboveground biomass production associated with metabolism-based resistance in the L. rigidum population studied (Vila-Aiub et al., 2005b). Should these results be of general applicability, the L1781 ACC allele might well be the gene endowing resistance to ACC-inhibiting herbicides that displays the lowest associated fitness penalty. In other words, the L1781 ACC allele would be the 'best' gene to be selected for by ACC-inhibiting herbicides in grass weed populations. Thus, a relevant issue for resistance management 
in species where L1781 ACC alleles have been reported, would be to design management tactics aimed at creating a field environment where a significant fitness penalty would exist for plants containing these alleles. This implies detecting phenotypic or developmental differences in plants containing L1781 ACC alleles, and exploiting them by appropriate cultural practices, as described for instance for the control of triazine-resistant slim amaranth (Amaranthus hybridus L.) plants (Jordan et al., 1999). For this purpose, data are needed regarding the possible pleiotropic effects associated with L1781 ACC alleles, should such effects exist. Biological studies conducted on a single rye-grass population showed that L1781 ACC alleles, despite not altering vegetative and reproductive growth (Vila-Aiub et al., 2005b), could have pleiotropic effects on the germination and emergence requirements of rye-grass plants (VilaAiub et al., 2005a). If this is a general feature of plants containing L1781 ACC alleles, then non-chemical cultural practices based upon soil cultivation should be effective in destroying these plants, especially in species such as $A$. myosuroides that are sensitive to cultural practices (Chauvel et al., 2001).

\section{Acknowledgements}

The authors are grateful to the Départements 'Santé des Plantes et Environnement' and 'Environnement et Agronomie' of the INRA and to the Conseil Régional de Bourgogne for financial support, to the Coopérative Dijon-Céréales for identifying the sampled fields, to all at the INRA, Dijon, who collected A. myosuroides seeds and to Aurélie Bérard and Nabila Barouahim (Centre National de Génotypage, Évry, France) for technical assistance in genotyping.

\section{References}

Barnes JW \& Oliver LR (2004) Cloransulam antagonizes annual grass control with aryloxyphenoxypropionate graminicides but not cyclohexanediones. Weed Technology $\mathbf{1 8}$, 763-772.

Buhler DD, Liebman M \& Obrycki JJ (2000) Theoretical and practical challenges to an IPM approach to weed management. Weed Science 48, 274-280.

Cavan G, Cussans J \& Moss S (2000) Modelling different cultivation and herbicide strategies for their effect on herbicide resistance in Alopecurus myosuroides. Weed Research 40, 561-568.

Cavan G, Cussans J \& Moss S (2001) Managing the risks of herbicide resistance in wild oat. Weed Science 49, 236-240.

Chauvel B, Gulllemin J-P, Colbach N \& Gasquez J (2001) Evaluation of cropping systems for management of herbicide-resistant populations of blackgrass (Alopecurus myosuroides Huds.). Crop Protection 20, 127-137.
Collings LV, Blair AM, Gay AP, Dyer CJ \& Mackay N (2003) The effect of weather factors on the performance of herbicides to control Alopecurus myosuroides in winter wheat. Weed Research 43, 146-153.

Cummins I, Cole DJ \& Edwards R (1999) A role for glutathione transferases functioning as glutathione peroxidases in resistance to multiple herbicides in black-grass. Plant Journal 18, 285-292.

Délye C (2005) Weed resistance to acetyl-coenzyme A carboxylase inhibitors: an update. Weed Science 53, 728-746.

Délye C \& Michel S (2005) 'Universal' primers for PCRsequencing of grass chloroplastic acetyl-CoA carboxylase domains involved in resistance to herbicides. Weed Research 45, 323-330.

Délye C, Calmès É \& MatéJicek A (2002a) SNP markers for black-grass (Alopecurus myosuroides Huds.) genotypes resistant to acetyl CoA-carboxylase inhibiting herbicides. Theoretical and Applied Genetics 104, 1114-1120.

Délye C, MatéJicek A \& Gasquez J (2002b) PCR-based detection of resistance to acetyl-CoA carboxylase-inhibiting herbicides in black-grass (Alopecurus myosuroides Huds) and ryegrass (Lolium rigidum Gaud). Pest Management Science 58, 474-478.

Délye C, Zhang X-Q, Chalopin C, Michel S \& Powles SB (2003) An isoleucine residue within the carboxyl-transferase domain of multidomain acetyl-CoA carboxylase is a major determinant of sensitivity to aryloxyphenoxypropionate but not to cyclohexanedione inhibitors. Plant Physiology 132, 1716-1723.

Délye C, Straub C, Michel S \& Le Corre V (2004) Nucleotide variability at the acetyl-coenzyme A carboxylase gene and the signature of herbicide selection in the grass weed Alopecurus myosuroides (Huds.). Molecular Biology and Evolution 21, 884-892.

Délye C, Zhang X-Q, Michel S, MatéJicek A \& Powles SB (2005) Molecular bases for sensitivity to acetyl-coenzyme A carboxylase inhibitors in black-grass. Plant Physiology 137, 794-806.

Diggle AJ, Neve PB \& Smith FP (2003) Herbicides used in combination can reduce the probability of herbicide resistance in finite weed populations. Weed Research $\mathbf{4 3}$, 371-382.

Foster DK, Ward P \& Hewson RT (1993) Selective grass-weed control in wheat and barley based on the safener fenchlorazole-ethyl. In: Proceedings of the 1993 Brighton Crop Protection Conference - Weeds, Brighton, UK, 1267-1272.

HEAP IM (2006) International survey of herbicide resistant weeds. http://www.weedresearch.com (accessed on 9 May 2006).

Jasieniuk M, Brûlé-Babel AL \& Morrison IN (1996) The evolution and genetics of herbicide resistance in weeds. Weed Science 44, 176-193.

Jordan N, Kelrick M, Brooks J \& Kinerk W (1999) Biorational management tactics to select against triazine-resistant Amaranthus hybridus: a field trial. Journal of Applied Ecology 36, 123-132.

Kudsk P \& Streibig JC (2003) Herbicides - a two-edged sword. Weed Research 43, 90-102.

Letouzé A \& Gasquez J (1999) A rapid reliable test for screening aryloxyphenoxypropionic acid resistance within Alopecurus myosuroides and Lolium spp populations. Weed Research 39, $37-48$. 
Letouzé A \& Gasquez J (2001) Inheritance of fenoxaprop-Pethyl resistance in a blackgrass (Alopecurus myosuroides Huds.) population. Theoretical and Applied Genetics 103, 288-296.

Maneechote C, Preston C \& Powles SB (1997) A diclofopmethyl-resistant Avena sterilis biotype with a herbicideresistant acetyl-coenzyme A carboxylase and enhanced metabolism of diclofop-methyl. Pesticide Science 49, 105114.

McFadden JJ, Frear DS \& Mansager ER (1989) Aryl hydroxylation of diclofop by a cytochrome P450 dependent monooxygenase from wheat. Pesticide Biochemistry and Physiology 32, 92-100.

Milner LJ, Reade JPH \& Cовв AH (2001) Developmental changes in gluthatione S-transferase activity in herbicideresistant populations of Alopecurus myosuroides Huds (black-grass) in the field. Pest Management Science 57, 11001106.

Roux F, Gasquez J \& Reboud X (2004) A spatially based concept to manage herbicide resistance: The mosaic strategy. In: XIIè
Colloque International sur la Biologie des Mauvaises Herbes, Dijon, France, 611-618.

Sauer S, Lechner D, Berlin K et al. (2000) A novel procedure for efficient genotyping of single nucleotide polymorphisms. Nucleic Acids Research 28, e13 (8 pages).

Tal A, Romano ML, Stephenson GR, Schwan AL \& Hall JC (1993) Glutathione conjugation: a detoxification pathway for fenoxaprop-ethyl in barley, crabgrass, oat and wheat. Pesticide Biochemistry and Physiology 46, 190-199.

Vila-Aiub MM, Neve P, Steadman KJ \& Powles SB (2005a) Ecological fitness of a multiple herbicide resistant Lolium rigidum population: dynamics of seed germination and seedling emergence of target-site versus metabolism-based resistant and susceptible phenotypes. Journal of Applied Ecology 42, 288-298.

Vila-Aiub MM, Neve P \& Powles SB (2005b) Resistance cost of a cytochrome $\mathrm{P} 450$ herbicide metabolism mechanism but not an ACCase target site mutation in a multiple resistant Lolium rigidum population. New Phytologist 167, 787-796. 